\title{
Chitosan-Based Anion Exchange Membranes for Direct Ethanol Fuel Cells
}

Birgit Feketeföldi', Bernd Cermenek ${ }^{2}$, Christina Spirk ${ }^{3}$, Alexander Schenk ${ }^{2}$, Christoph Grimmer ${ }^{2}$, Merit Bodner ${ }^{2}$, Martin Koller ${ }^{3}$, Volker Ribitsch $^{3}$ and Viktor Hacker ${ }^{2 *}$

${ }^{1}$ Institute for Surface Technologies and Photonics, JOANNEUM RESEARCH Forschungsgesellschaft mbH/Materials, Franz-Pichler-Straße 30 , 8160 Weiz, Austria 2Institute of Chemical Engineering and Environmental Technology, Fuel Cell Systems Group, Graz University of Technology, NAWI Graz, Inffeldgasse 25C, 8010 Graz, Austria

${ }^{3}$ Institute of Chemistry, University of Graz, Heinrichstraße 28, 8010 Graz, Austria

\begin{abstract}
A series of novel cross-linked highly quaternized chitosan and quaternized poly (vinyl alcohol) membranes were successfully synthesized to be applied in alkaline direct ethanol fuel cells. Cross-linking was accomplished using two different cross-linking agents and an additional thermal process to improve both chemical and thermal properties. Equivalent blends of chitosan and poly (vinyl alcohol) membranes with various degrees of cross-linking were prepared by using different amounts of glutaraldehyde and ethylene glycol diglycidyl ether as cross-linkers. To investigate their applicability in direct ethanol fuel cells, the membranes were characterized in terms of their structural properties, chemical, thermal and alkaline stability, ion transport and ionic properties using following methods: Fourier transform infrared spectroscopy, nuclear magnetic resonance spectroscopy, scanning electron microscopy, thermogravimetric analysis, water uptake by mass change, ethanol permeability in the diffusion cell, back titration method (ion exchange capacity) and electrochemical impedance spectroscopy (anion conductivity).

Despite the high degree of quaternization of the applied materials and regardless of the thin film thickness of the blend membranes, the novel cross-linked products displayed outstanding mechanical stability. The lower crosslinked membranes exhibited the best transport and ionic properties with a high anion conductivity of $0.016 \mathrm{~S} \mathrm{~cm}^{-1}$ and a high ion exchange capacity of $1.75 \mathrm{meq} \mathrm{g}^{-1}$, whereas membranes with a higher degree of cross-linking performed superior in terms of reduced ethanol permeability of $3.30 \cdot 10^{-7} \mathrm{~cm}^{2} \mathrm{~s}^{-1}$ at $60^{\circ} \mathrm{C}$. The blend membranes - chemically and thermally cross-linked - provide excellent thermal stability with an onset degradation temperature above $280^{\circ} \mathrm{C}$ and superb alkaline stability in $1.0 \mathrm{M} \mathrm{KOH}$ at $60^{\circ} \mathrm{C}$ for $650 \mathrm{~h}$. Therefore, these composite membranes exhibit high potential for application as alkaline electrolytes in fuel cells.
\end{abstract}

Keywords: Annealing; Chitosan; Cross-linking; Direct ethanol fuel cells; Ethanol permeability; Poly(vinyl alcohol); Quaternized anion exchange membrane

\section{Introduction}

The direct ethanol fuel cell (DEFC) is a promising candidate for supplying portable applications such as laptops and mobile phones with electricity from a liquid fuel, i.e., ethanol [1]. In this process, the chemical energy of ethanol is directly converted into electrical energy. The development and optimization of the fuel cell components such as membranes and catalysts is decisive to enhance their power density.

In general, the use of anion exchange membranes (AEMs) in alkaline fuel cells facilitates: I. The use of non-noble metals such as nickel, cobalt, manganese or iron as electro-catalysts [2,3], II. The reduction of fuel crossover due to the reversed direction of hydroxide ions (electroosmotic drag) compared to proton conductive membranes [4], III. The suppression of carbonate formation (by substitution of liquid alkaline electrolyte without mobile cations) [3] and, IV. The simplification of water management [3]. Due to alkaline conditions, the kinetics of both ethanol oxidation reaction (EOR) and oxygen reduction reaction (ORR) are enhanced and the costs of the DEFC components (catalyst and membrane) might be reduced [2,5].

An applicable AEM will have feasible transport and ion-exchange capabilities, mechanical and thermochemical stabilities, low degree of alkaline swelling and minor alcohol crossover. As demonstrated previously, a successful procedure utilizes blends of two or more polymers to combine the desirable properties of each component while reducing the shortcomings of the single polymers to obtain solid electrolyte membranes for fuel cells with a high quality [6-10].
Several techniques have been employed to prepare various alkaline anion-exchange membranes for fuel cell application, and distinguished reviews and original articles are available in literature [3,11-13]. Chitosan constitutes a polymer accessible from alkaline or enzymatic deacetylation of chitin of fungal or animal origin. The polymer displays perfect membrane properties and, due to its exchangeable functional groups, the polymer can easily be modified [14]. Poly (vinyl alcohol) (PVA) is an inexpensive semi-crystalline polyhydroxy polymer, and has also excellent film-forming properties and a high density of reactive chemical functions [15].

A common strategy of introducing ionic conductive groups into polymeric matrices is the quaternization with a clear preference for trimethylammonium $\left(-\mathrm{N}\left(\mathrm{CH}_{3}\right)_{3}\right)$ groups onto the backbone or side

*Corresponding authors: Bernd Cermenek, Institute of Chemical Engineering and Environmental Technology, Fuel Cell Systems Group, Graz University of Technology, NAWI Graz, Inffeldgasse 25C, 8010 Graz, Austria, Tel: +43 316873 8788; E-mail: bernd.cermenek@tugraz.at

Viktor Hacker, Institute of Chemical Engineering and Environmental Technology Fuel Cell Systems Group, Graz University of Technology, NAWI Graz, Inffeldgasse 25C, 8010 Graz, Austria, Tel: +43 316873 8780; Fax: +43 316873 8782; E-mail: viktor.hacker@tugraz.at

Received January 27, 2016; Accepted February 14, 2016; Published February 16,2016

Citation: Feketeföldi B, Cermenek B, Spirk C, Schenk A, Grimmer C, et al. (2016) Chitosan-Based Anion Exchange Membranes for Direct Ethanol Fuel Cells. J Membra Sci Technol 6: 145. doi:10.4172/2155-9589.1000145

Copyright: (c) 2016 Feketeföldi B, et al. This is an open-access article distributed under the terms of the Creative Commons Attribution License, which permits unrestricted use, distribution, and reproduction in any medium, provided the original author and source are credited. 
chains of the polymers [15-21]; this ensures a better chemical stability than other functional groups such as pyridinium, sulfonium and imidazolium [22]

Quaternized polymers have a high degree of hydrophilicity clearly evident in the high degree of swelling, thus resulting in modest membrane strength. To prepare durable membranes for fuel cells in alkaline medium with improved chemical and mechanical stability, suitable cross-linking agents must be chosen to form three dimensional networks of the water soluble polymers [23,24].

Both chitosan and PVA can be cross-linked by various dialdehydes such as glyoxal (GO) or glutaraldehyde (GA) $[25,26]$, and by epoxide compounds such as epichlorohydrin (ECH) or ethylene glycol diglycidyl ether (EGDGE) [27]. Another cross-linking system for chitosan and PVA-derivatives represents 1-ethyl-3-(3-dimethylaminopropyl) carbodiimide (EDC) and N-hydroxysuccinimide (NHS) as catalyst. These compounds have been successfully used for wound dressing and biomedical applications as non-poisonous and biocompatible cross-linking systems [28]. Dialdehydes react with the alcohol groups of PVA and amine groups of chitosan to form stable acetal and imine bonds, respectively. The epoxide compounds form networks with the hydroxide and amine groups of the polymers by opening the epoxide. The carbodiimide compounds, in combination with a catalyst, crosslink primary amines to yield amide bonds. In addition, the crosslinking can be supported by thermal treatment (annealing) [29], which can improve the thermal and chemical properties of the composite membrane.

Preparation of quaternized PVA/chitosan with the aforementioned cross-linking agent GA has been reported to improve the mechanical stability and the electrochemical performance [20,21], whereas the chemical stability of the membranes was not reported although, at present, this constitutes a critical parameter for alkaline DEFCs. By the use of GA, only a limited degree of quaternization (DQ) of chitosan (DQ less than approximately 35\%) is allowed in order to obtain a three dimensional network with sufficient chemical properties [30]. To obviate this limitation, at first the synthesis of quaternized PVA and quaternized chitosan with a DQ of $2.6 \%$ and $39 \%$, respectively, was performed; afterwards, quaternized chitosan nanoparticles were introduced into the composite membrane to increase the ionic conductivity [31].

To the best of our knowledge, this research is the first attempt to synthesize composite membranes on the basis of highly quaternized chitosan (DQ higher than 80\%) and quaternized PVA by cross-linking with two different agents and an additional annealing process. The aim of the present work was to improve the performance of the membrane in highly alkaline media by a novel cross-linking strategy for the membrane with improved chemical and thermal properties. GA and EGDGE were alternatingly introduced to the membranes, in which the amount of the first crosslinking agents was varied and the second cross-linker was constant. The cross-linked membranes have been characterized by Fourier transform infrared spectroscopy (FT-IR), scanning electron microscopy (SEM) and thermogravimetric analysis (TGA) techniques. Water uptake, anion conductivity, ion-exchange capacity (IEC) and ethanol permeability were measured as a function of the degree of cross-linking under alkaline conditions. Studies on chemical stability of the differently cross-linked membranes were also reported.

\section{Experimental}

\section{Materials}

Chitosan, poly (vinyl alcohol) (PVA), (2,3-Epoxypropyl) trimethylammonium chloride (EPTMAC), ethylene glycol diglycidyl ether (EGDGE), glutaraldehyde (GA, 25 wt.-\% content in distilled water) were supplied in p.a. quality by Sigma-Aldrich Handels $\mathrm{GmbH}$, Austria, and were used without further purification. PVA had a degree of polymerization of 1600 and a hydrolysis degree of 97.5-99.5 mol\%. Chitosan had a degree of deacetylation of $92 \%$.

\section{Preparation of HTCC}

$\mathrm{N}$-[(2-Hydroxy-3-trimethylammonium)propyl] chitosan chloride (HTCC) was prepared based on a method similar to those already described elsewhere [32]. Briefly, chitosan (3.0 g, $18.6 \mathrm{mmol}$ ) was dispersed in deionized water at $80^{\circ} \mathrm{C}$. EPTMAC $(11.3 \mathrm{~g}, 74.4 \mathrm{mmol})$ was added to chitosan suspension. After reaction for $4 \mathrm{~h}$ at $80^{\circ} \mathrm{C}$, the reaction solution was poured into cold acetone and stirred overnight in a refrigerator. The white precipitated product was collected by filtration and dried at $60^{\circ} \mathrm{C}$.

\section{Preparation of quaternized PVA}

Quaternized PVA (QPVA) was prepared by a method similar to those described elsewhere [33]. Briefly, PVA $(3.0 \mathrm{~g}, 66.7 \mathrm{mmol})$ was dissolved in deionized water under stirring at $95^{\circ} \mathrm{C}$. Then $2.0 \mathrm{M} \mathrm{KOH}$ solution (2.5 g, $4.5 \mathrm{mmol})$ and EPTMAC (5.0 g, $32.9 \mathrm{mmol})$ were added. The reaction was allowed to proceed for $4 \mathrm{~h}$ at $65^{\circ} \mathrm{C}$ while stirring. Then the mixture was deposited and washed three times by anhydrous ethanol. The product was dried at $60^{\circ} \mathrm{C}$ in vacuum to obtain white solid quaternized PVA (QPVA).

\section{Preparation of the cross-linked quaternized Chitosan/QPVA membrane}

QPVA was dissolved in deionized water under stirring at $90^{\circ} \mathrm{C}$ for one hour in order to prepare a $5 \mathrm{wt}$ - $\%$ solution, and the $\mathrm{pH}$-value adjusted to 5.0 with $1.0 \mathrm{~N} \mathrm{HCl}$ solution. To this solution, a prescribed amount of 10 wt.-\% GA was added under stirring (Table 1). After dissolving HTCC in $1 \mathrm{wt}$. $\%$ acetic acid solution, yielding a $5 \mathrm{wt} .-\%$ solution, a prescribed amount of 10 wt.-\% EGDGE in ethanol was added (Table 2). The mixture was stirred at $60^{\circ} \mathrm{C}$ for $1 \mathrm{~h}$. QPVA $(5 \mathrm{~g})$ and HTCC ( $5 \mathrm{~g})$ were mixed and filtered with a $5 \mu \mathrm{m}$ PTFE membrane filter. The solution was coated onto the surface of a plexiglass petri dish and dried at $60^{\circ} \mathrm{C}$ overnight. Afterwards, the membrane was dried at $130^{\circ} \mathrm{C}$ for $2 \mathrm{~min}$.

Two different series of HTCC/QPVA membranes were prepared.

\begin{tabular}{|c|c|c|}
\hline Membrane a,b,c & $\begin{array}{l}\text { Molar ratio of GA to } \\
\text { membrane }\left[\mathrm{mmol} \mathrm{mmol}^{-1}\right]\end{array}$ & $\begin{array}{c}\text { Degree of cross-linking } \\
\text { QPVA [\%] }\end{array}$ \\
\hline HTCC/QPVA-a & $0.20 / 2.2$ & 9.1 \\
\hline HTCC/QPVA-b & $0.30 / 2.2$ & 13.7 \\
\hline HTCC/QPVA-C & $0.45 / 2.2$ & 20.4 \\
\hline HTCC/QPVA-d & $0.60 / 2.2$ & 27.4 \\
\hline HTCC/QPVA-e & $0.90 / 2.2$ & 41.1 \\
\hline HTCC/QPVA-f & $1.10 / 2.2$ & 50.3 \\
\hline
\end{tabular}

aAll membranes were prepared using a same kind of HTCC and QPVA, the degree of quaternization (DQ) was $90.4 \%$ and $9.0 \%$, respectively, determined by elemental analysis.

'The molar ratio of EGDGE to composite membrane was $0.3 / 2.2 \mathrm{mmol} \mathrm{mmol}^{-1}$ having a degree of crosslinking (DC) of $13.1 \%$.

cThe thickness of membranes was $45 \mathrm{~nm},+/-3 \mathrm{~nm}$ dry state.

Table 1: Cross-linking conditions for HTCC/QPVA composite membrane with GA. 


\begin{tabular}{|c|c|c|}
\hline Membrane $^{a, b, c}$ & $\begin{array}{l}\text { Molar ratio of EDGE to } \\
\text { membrane }\left[\mathrm{mmol} \mathrm{mmol}^{-1}\right]\end{array}$ & $\begin{array}{c}\text { Degree of cross-linking } \\
\text { HTCC [\%] }\end{array}$ \\
\hline HTCC/QPVA-1 & $0.20 / 2.2$ & 8.8 \\
\hline HTCC/QPVA-2 & $0.30 / 2.2$ & 13.1 \\
\hline HTCC/QPVA-3 & $0.43 / 2.2$ & 19.7 \\
\hline HTCC/QPVA-4 & $0.60 / 2.2$ & 26.3 \\
\hline HTCC/QPVA-5 & $0.90 / 2.2$ & 39.4 \\
\hline HTCC/QPVA-6 & $1.10 / 2.2$ & 49.5 \\
\hline \multicolumn{3}{|c|}{$\begin{array}{l}\text { All membranes were prepared using a same kind of } \mathrm{HTCC} \text { and QPVA, the } \\
\text { degree of quaternization (DQ) was } 90.4 \% \text { and } 9.0 \% \text {, respectively, determined } \\
\text { by elemental analysis. } \\
\text { The molar ratio of GA to composite membrane was } 0.3 / 2.2 \mathrm{mmol} \mathrm{mmol}^{-1} \text {, } \\
\text { having a degree of crosslinking (DC) of } 13.7 \% \text {. } \\
\text { The thickness of membranes was } 35 \mathrm{~nm},+/-4 \mathrm{~nm} \text { dry state. }\end{array}$} \\
\hline
\end{tabular}

Table 2: Cross-linking conditions for HTCC/QPVA composite membrane with EGDGE.

In the first series, the membranes were cross-linked with varying amounts of GA, while the amount of the second cross-linking reagent (EGDGE) was maintained constant. These series are referred to as HTCC/QPVA-i (i = a, b, c, d, e and f).

In contrast to the aforementioned membrane series, the HTCC/ QPVA-j (1, 2, 3, 4, 5 and 6) membranes were cross-linked with varying amounts of EGDGE, while the concentration of GA remained constant.

\section{Methods}

Degree of membrane cross-linking: The degree of membrane cross-linking for QPVA and HTCC with glutaraldehyde (GA) and ethylene glycol diglycidyl ether (EGDGE), respectively, was calculated according to Equation 1 [34].

$$
\mathrm{DC}(\%)=\frac{10 \% \times V_{\text {Agent }} / M w_{\text {Agent }}}{5 \% \times V_{Q-\text { Polymer }} / M w_{Q-\text { Polymer }}} \times 100 \%
$$

where DC (\%) is the molar ratio of GA/EGDGE to the composite membrane in repeat units, $\mathrm{V}_{\text {Agent }}$ is the volume $(\mathrm{mL})$ of cross-linking agent (GA or EGDGE, 10 wt.- $\%), \mathrm{V}_{\text {Q-Polymer }}$ is the volume $(\mathrm{mL})$ of quaternized polymer solution (QPVA and HTCC, 5 wt.-\%), $M_{w, \text { Agent }}$ is the molecular weight of GA (100.12 $\left.\mathrm{g} \mathrm{mol}^{-1}\right)$ and EGDGE (174.19 $\mathrm{g} \mathrm{mol}^{-1}$ ), respectively. $\mathrm{M}_{\mathrm{w}, \mathrm{Q}-\mathrm{Polymer}}$ is corresponding to the averaged molecular weight of HTCC/QPVA monomers $\left(228.80 \mathrm{~g} \mathrm{~mol}^{-1}\right)$.

Water uptake: Water uptake of the membranes was carried out by measuring the change in mass of the membranes before and after hydration. The membranes were immersed in distilled water at room temperature (RT) for $24 \mathrm{~h}$. Then the surplus water was wiped with filter paper and weighted immediately. The percentage water uptake $\mathrm{W}$ was calculated using the following relation (Equation 2):

$$
\mathrm{W}(\%)=\frac{m_{w-} m_{w}}{m_{d}} \times 100
$$

where $m_{w}$ is the mass $\left[\mathrm{g}\right.$ ] of wet membrane and $m_{d}$ is the mass [g] of dry membrane.

Ion exchange capacity (IEC): The ion exchange capacity (IEC) was measured by back titration. Therefore, membranes $(0.2 \mathrm{~g})$ were soaked in $1.0 \mathrm{M} \mathrm{KOH}$ for $24 \mathrm{~h}$, washed with deionized water and equilibrated with $40 \mathrm{~mL}$ of $0.01 \mathrm{M} \mathrm{HCl}$ standard solution for $24 \mathrm{~h}$, followed by potentiometric titration with $0.01 \mathrm{M} \mathrm{NaOH}$ standard solution. $40 \mathrm{~mL}$ of $0.01 \mathrm{M} \mathrm{HCl}$ standard solution was used as blank sample. The IEC value was calculated by the following Equation 3:

$$
\mathrm{IEC}=\frac{\left(V_{\text {blank }}-V_{\text {membrane }}\right) \cdot \mathrm{CHCl}}{m_{d}} \times 1000
$$

where $\mathrm{V}_{\text {blank }}$ and $\mathrm{V}_{\text {membrane }}$ were the consumed volumes $[\mathrm{mL}$ ] of the $\mathrm{NaOH}$ solution for the blank sample and the HTCC/QPVA membrane sample, respectively, $\mathrm{C}_{\mathrm{HCl}}$ was the concentration $[\mathrm{M}]$ of $\mathrm{HCl}$ solution, and $\mathrm{m}_{\mathrm{w}}$ is the mass $[\mathrm{g}]$ of dry membrane sample.

Ethanol permeability: The ethanol permeability was measured by a diffusion cell comprising two compartments [21]. The membrane was clamped between the two compartments. One compartment was loaded with deionized water and the other with $1.0 \mathrm{M}$ ethanol solution. The solutions in each compartment were agitated with magnetic stirrers. And the concentration of permeated ethanol was measured by refractive index (Smartline RI Detector 2300 Knauer).

Anion conductivity: The membrane resistances of five HTCC/ QPVA-(2-6) membranes with different degrees of cross-linking of EGDGE (2: 13.1\%, 3: 19.7\%, 4: 26.3\%, 5: 39.4\% and 6: 49.5\%) and five HTCC/QPVA-(b-f) membranes with different degrees of crosslinking of GA (b: $13.7 \%$, c: $20.4 \%$, d: $27.4 \%$, e: $41.1 \%$ and f: $50.3 \%$ ) were determined by means of electrochemical impedance spectroscopy (EIS) using a Gamry Reference 600 Potenstiostat and a Conductivity Clamp (Bekktech BT110 LLC, Scribner Associates, Southern Pines, $\mathrm{NC}$, USA). For the measurements, a piece of each membrane (b- $\mathrm{f}$ and 2-6) in size of $2.5 \times 1.0 \mathrm{~cm}$ (in dry state) was alkalized in a $1.0 \mathrm{M} \mathrm{KOH}$ solution for approximately $24 \mathrm{~h}$. After alkalization, the membrane was rinsed with ultra-pure water $(\sim 18 \mathrm{M} \Omega \mathrm{cm})$ and then immersed in ultra-pure water for another $24 \mathrm{~h}$. Finally, the full hydrated membrane sample was incorporated into the four electrode configuration of the conductivity clamp and placed into ultra-pure water. The conducted measuring procedure has been reported previously [35-37].

In short, all measurements were carried out at RT in potentiostatic mode and 5 points per decade were recorded. At the beginning of each measurement, the open circuit potential (OCP) was recorded for 50 seconds. Afterwards a sinusoidal alternating current (AC) voltage of $50 \mathrm{mV}$ was applied in a frequency range of $0.1-10000 \mathrm{~Hz}$. The resulting sinusoidal AC current was used to measure the impedance $\mathrm{Z}$ of the membrane. The frequency-independent measured resistance $\mathrm{R}_{\text {tot }}$ of respective membrane was determined from the high frequency range (HFR) intercept in the corresponding Nyquist plots. The real membrane resistance $\mathrm{R}_{\text {membrane }}$ was calculated using Equation 4 under consideration of the electrolyte resistance $\mathrm{R}_{\mathrm{UPW}, \text { after }}$ (Table 3) [35-37].

$$
\frac{1}{\mathrm{R}_{\text {tot }}}=\frac{1}{\mathrm{R}_{\text {membrane }}}+\frac{1}{\mathrm{R}_{\mathrm{UPW}, \text { after }}}
$$

For calculating the in-plane anion conductivity (see Equation 5 ), the thickness $T$ of the respective membrane was measured in wet state by using a micrometer screw (10-fold determination) (Table 3 ). The parameter $\mathrm{d}$ denotes the distance between inner sense electrodes $(=0.425 \mathrm{~cm})$ of the conductivity clamp; while $\mathrm{W}$ is the width of the membrane in wet state (Table 3) [35-37].

$$
\sigma_{\text {membrane }}=\frac{\mathrm{d}}{\mathrm{R}_{\text {membrane }} \cdot \mathrm{T} . \mathrm{W}}
$$

Membrane characterizations: The chemical stability in alkaline medium was evaluated by immersing the membranes in $1.0 \mathrm{M} \mathrm{KOH}$ solution at $60^{\circ} \mathrm{C}$ for different periods of time. The compactness and appearance of leaks of the membranes was visually observed. The chemical stability of the membranes in alkaline medium was also investigated by monitoring the ethanol permeability as a function of immersion in $1.0 \mathrm{M} \mathrm{KOH}$ solutions at RT for $24 \mathrm{~h}$ and $168 \mathrm{~h}$. The structure of the chemically cross-linked composite membranes was 
Citation: Feketeföldi B, Cermenek B, Spirk C, Schenk A, Grimmer C, et al. (2016) Chitosan-Based Anion Exchange Membranes for Direct Ethanol Fuel Cells. J Membra Sci Technol 6: 145. doi:10.4172/2155-9589.1000145

Page 4 of 9

\begin{tabular}{|c|c|c|c|c|c|c|c|c|c|}
\hline Membrane & ${ }^{\mathrm{a}} \mathbf{R}_{\text {UPW,before }}[\mathbf{\Omega}]$ & ${ }^{\mathrm{b}} \mathbf{R}_{\mathrm{UPW}, \text { after }}[\mathbf{\Omega}]$ & $\mathbf{R}_{\text {tot }}[\mathbf{\Omega}]$ & $\mathbf{R}_{\text {memb. }}[\Omega]$ & $\mathrm{d}[\mathrm{cm}]$ & $\mathrm{T}[\mathrm{cm}]$ & $\mathrm{W}[\mathrm{cm}]$ & ${ }^{\mathrm{c}} \rho[\Omega \cdot \mathrm{cm}]$ & $\sigma\left[\mathrm{mS} \cdot \mathrm{cm}^{-1}\right]$ \\
\hline HTCC/QPVA-b & 243796 & 254656 & 4752 & 4842 & 0.425 & 0.0065 & 1.2 & 89 & 11.22 \\
\hline HTCC/QPVA-C & 219702 & 229570 & 6600 & 6796 & 0.425 & 0.0051 & 1.2 & 97 & 10.30 \\
\hline HTCC/QPVA-d & 228244 & 239416 & 6272 & 6441 & 0.425 & 0.0058 & 1.2 & 105 & 9.48 \\
\hline HTCC/QPVA-e & 210739 & 233521 & 6392 & 6572 & 0.425 & 0.0070 & 1.2 & 130 & 7.68 \\
\hline HTCC/QPVA-f & 199585 & 230983 & 7031 & 7251 & 0.425 & 0.0063 & 1.2 & 129 & 7.73 \\
\hline HTCC/QPVA-2 & 235029 & 237083 & 4564 & 4654 & 0.425 & 0.0047 & 1.2 & 62 & 16.09 \\
\hline HTCC/QPVA-3 & 219180 & 279603 & 9787 & 10143 & 0.425 & 0.0032 & 1.2 & 90 & 11.09 \\
\hline HTCC/QPVA-4 & 257922 & 253250 & 7521 & 7751 & 0.425 & 0.0038 & 1.2 & 83 & 12.09 \\
\hline HTCC/QPVA-5 & 213628 & 227102 & 8658 & 9001 & 0.425 & 0.0035 & 1.2 & 89 & 11.21 \\
\hline HTCC/QPVA-6 & 269105 & 268272 & 7791 & 8024 & 0.425 & 0.0046 & 1.2 & 104 & 9.66 \\
\hline
\end{tabular}

Table 3: Determined anion conductivities of all cross-linked HTCC/QPVA membranes resulting from adjacent measuring parameters.

characterized by Fourier transform infrared spectroscopy (FT-IR). The infrared spectrometer (Bruker Tensor 27) was used to obtain spectra in the range from 4000 to $600 \mathrm{~cm}^{-1}$ with a wavenumber resolution of $4 \mathrm{~cm}^{-1}$. Nitrogen microanalysis was performed by elemental analysis (Multiprobe UHV-surface-analysis system, Omicron Nanotechnology). Thermal gravimetric analysis (TGA) was conducted using a TGA/DSC system (NETZSCH STA 449, Germany). Samples were heated from 25 to $600^{\circ} \mathrm{C}$ at a heating rate of $10^{\circ} \mathrm{C} \mathrm{min}{ }^{-1}$ using a flow of $20 \mathrm{~mL} \mathrm{~min}^{-1}$ nitrogen as inert gas. The morphology of composite membranes was evaluated using a JEOL JSM 5600 scanning electron microscope (SEM) operating at $5 \mathrm{kV}$. The membranes were fractured in liquid nitrogen and sputtered with gold, then examined at 2000-fold magnifications. ${ }^{1} \mathrm{H}-\mathrm{NMR}$ measurements were performed on a nuclear magnetic resonance spectrometer Bruker Avance spectrometer at 300 $\mathrm{MHz}$ Ultrashield. QPVA powder was dissolved in 0.1-0.3 vol.\% $\mathrm{D}_{2} \mathrm{O}$ and stirred at $85^{\circ} \mathrm{C}$ for $1 \mathrm{~h}$. HTCC powder was dissolved in $0.1-0.3$ vol. $\% \mathrm{CD}_{3} \mathrm{COOD} / \mathrm{D}_{2} \mathrm{O}$.

\section{Results and Discussion}

\section{Membrane preparation}

For the quaternization of PVA and chitosan, the reagent EPTMAC was used. Figures 1 and 2 shows the ${ }^{1} \mathrm{H}-\mathrm{NMR}$ spectra of QPVA and HTCC. The peak at $3.1 \mathrm{ppm}$ was attributed to the methyl protons of the quaternary ammonium salt group. According to ${ }^{1} \mathrm{H}-\mathrm{NMR}$ spectra, successful quaternization of chitosan and PVA was confirmed. The nitrogen content of the quaternized polymers was measured by elemental analysis and the calculation of DQ was performed as described elsewhere [19,32]. The degree of quaternization of the resulting quaternized chitosan and QPVA was $90.4 \%$ and $9.0 \%$, respectively.

\section{Cross-linking HTCC/QPVA membranes}

As mentioned in the experimental section, the novel composite membranes were prepared from chitosan and PVA via quaternization and cross-linking, whereas cross-linking represents the most important step. The hydrophilicity of HTCC and QPVA was increased by introducing quaternary ammonium groups. To reduce water solubility of polymers and to increase chemical, mechanical and thermal stability, the composites were cross-linked in order to form three dimensional polymer networks. The effect of degree of cross-linking on the membranes structure and the chemical/physical properties were investigated. In this work we used GA and EGDGE to cross-link the polymer membranes. The amount of the first crosslinking agents was varied, whereas the amount of the second cross-linker was constant.
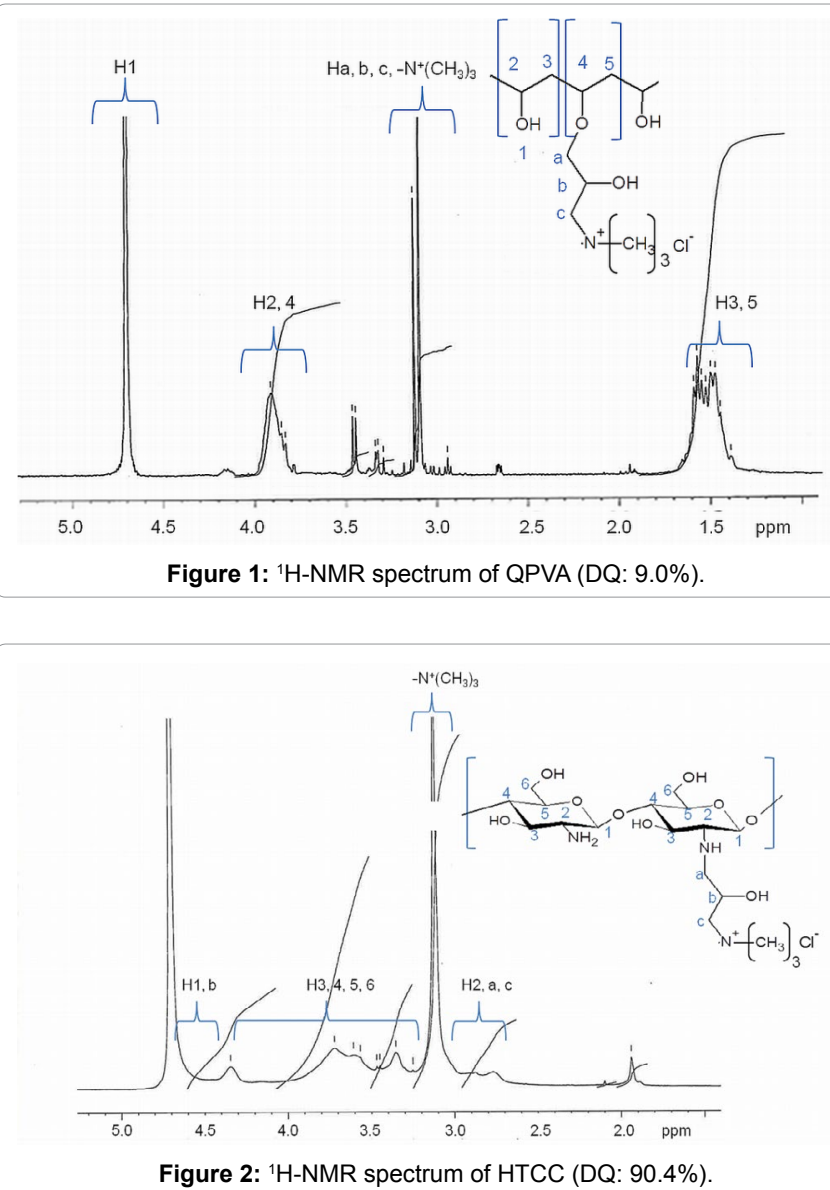

It is well known that GA is a common cross-linking agent for PVA and chitosan. The network formation takes place between the hydroxide groups of PVA, the amino groups of chitosan and the aldehyde groups of GA. However, a high degree of quaternization (DQ) of the chitosan induced a limitation of free amino groups, which basically caused GA to not work efficiently enough to cross-link the polymer and therefore less mechanically and chemically stable composite membranes were obtained. According to literature [38] higher cross-linked networks can be achieved by reduction of the degree of quaternization of chitosan. Nevertheless a reduction of DQ results in a decrease of ionic exchange capacity and a weaker specific anion conductivity of the membrane. 
For the anion conductivity to be as high as possible, a second crosslinking agent - EGDGE - was used in this work. Due to the presence of two reactive epoxy groups, EGDGE facilitates the cross-linking reaction with two amino groups of two different quaternized chitosan molecules and two hydroxyl functions of two PVA molecules during drying process [39]. This covalent linkage allowed the preparation of HTCC/QPVA composite membranes with quaternized chitosan with a DQ higher than $80 \%$. In addition to cross-linking by GA and EGDGE, PVA exhibits hydroxyl groups which are capable of forming hydrogen bonds with the hydroxyl groups of HTCC, thus completing the formation of the polymer network as shown in Figure 3.

The cross-linking conditions for these membranes are summarized in Tables 1 and 2. In the present study, all cross-linked membranes were prepared using HTCCs and QPVAs with a DQ higher than $80 \%$ and $5 \%$, respectively. The stability of the membranes toward alkaline media was observed visually from physical appearance (fragmented membranes) of the membranes after immersion in $1.0 \mathrm{M} \mathrm{KOH}$ solution for a certain period of time. With a cross-linking density, lower than the selected value, highly swollen membranes with poor mechanical properties were obtained leading to unexaminable membranes. By increasing the amount of cross-linker, the membranes became more stable with an optimum range of $0.3 / 2.2 \mathrm{mmol} \mathrm{mmol}^{-1}$ for GA and $0.43 / 2.2 \mathrm{mmol}$ $\mathrm{mmol}^{-1}$ for EGDGE. The alkaline stability of these membranes sustained on average for $650 \mathrm{~h}$ in $1.0 \mathrm{M} \mathrm{KOH}$ solution at $60^{\circ} \mathrm{C}$. Higher amounts of GA or EGDGE with a molar ratio of $0.6 / 2.2 \mathrm{mmol} \mathrm{mmol}^{-1}$ caused the membranes to exhibit less mechanical characteristics and crumbling behaviour due to the formation of rigid structure with poor hydration. Comparably to EGDGE, the membranes cross-linked by GA exhibited less mechanical strength. The higher cross-linked membranes were merely stable in $1.0 \mathrm{M} \mathrm{KOH}$ solution at $60^{\circ} \mathrm{C}$ for $290 \mathrm{~h}$. It is possible that, by raising the amount of cross-linker, the bond cleavage between HTCC/QPVA and GA/EGDGE increases, thus leading to a binding of water molecules to the polymers. Consequently, the networks became

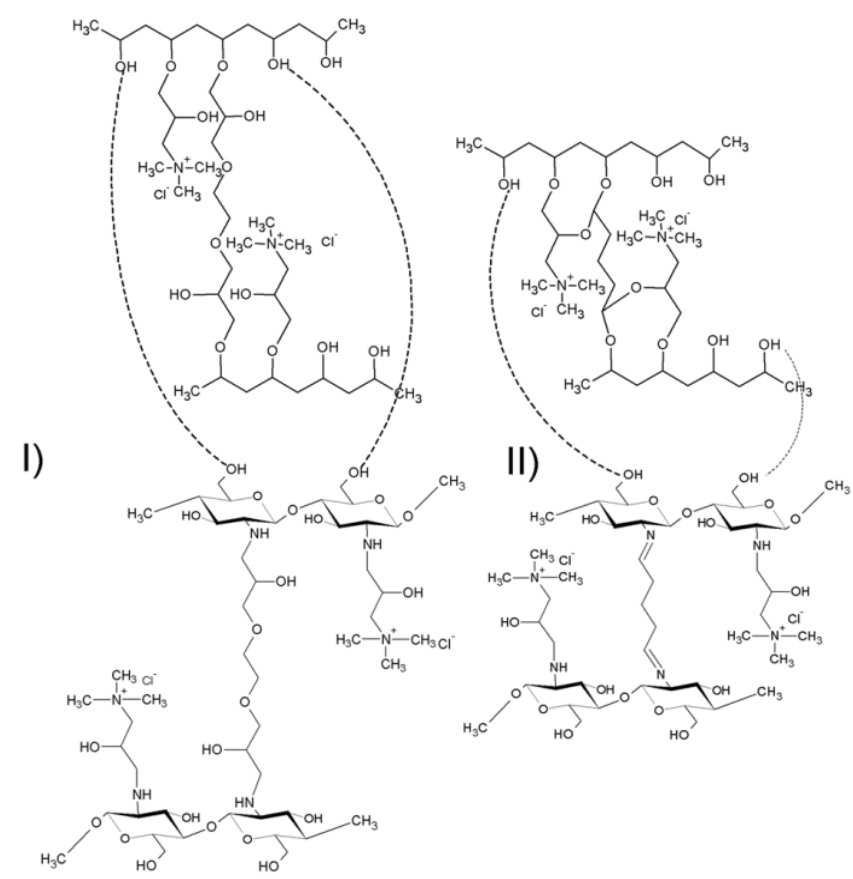

Figure 3: Illustration of cross-linking of HTCC and QPVA by I) ethylene glycol diglycidyl ether (EGDGE) and II) glutaraldehyde (GA). fragile and instable. All prepared membranes underwent an additional heat treatment at $130^{\circ} \mathrm{C}$ for two minutes (annealing) after basic drying at $60^{\circ} \mathrm{C}$ overnight. The membranes showed less elastic properties in dry condition, but a higher alkaline stability in $1.0 \mathrm{M} \mathrm{KOH}$ solution at $60^{\circ} \mathrm{C}$. A chemical stability for $650 \mathrm{~h}$ of all cross-linked membranes was obtained.

\section{Fourier transform infrared spectroscopy (FT-IR)}

The FT-IR spectra of the composite membrane HTCC/QPVA and the cross-linked membranes with GA $\left(0.6 / 2.2 \mathrm{mmol} \mathrm{mmol}^{-1}\right)$, EGDGE $\left(0.6 / 2.2 \mathrm{mmol} \mathrm{mmol}^{-1}\right)$ and GA/ EGDGE (each with $0.6 \mathrm{mmol}$ ) are shown in Figure 4. The two peaks at 840 and $1250 \mathrm{~cm}^{-1}$ in the spectra of the composite membranes are characteristics of $\mathrm{C}-\mathrm{N}$ bonds. The two signals at 1560 and $1650 \mathrm{~cm}^{-1}$ for quaternized chitosan are assigned to the N-H bending of primary and secondary amines, respectively [40]. A strong absorption band at $1440 \mathrm{~cm}^{-1}$ was recorded, corresponding to the $\mathrm{C}-\mathrm{H}$ bending of trimethylammonium groups, which shows the introduction of quaternary ammonium salt groups on the backbones of chitosan and PVA, respectively [30]. A broad band around 3300 $\mathrm{cm}^{-1}$ was attributed to the hydroxyl groups. It is also noted that a new absorption peak at $2870 \mathrm{~cm}^{-1}$ for the cross-linked membranes was observed, corresponding to $-\mathrm{CH}_{2}$ bending with QPVA and HTCC cross-linked by EGDGE and GA.

\section{Water uptake}

Membranes used as electrolyte in fuel cells work well within an optimum region for water uptake. The presence of water affects the ionic properties and the chemical and mechanical stability of the membranes. The concurrent swelling is related to the amount of polymer cross-linking agents, the thickness of the dry membrane and the hydrophilic properties due to the quaternary ammonium groups. It is possible that membranes exhibiting too high water uptake restrict the preparation of membrane electrode assembly (MEA) by decreasing contact between the active layer of the electrodes and the membrane. Studies are currently carried out on the assembly of MEA with novel HTCC/QPVA membranes and will be published at a future date.

All membranes were prepared using the same kind and composition of HTCC and QPVA with a DQ of $90.4 \%$ and $9.0 \%$, respectively. The amount of ammonium groups of the composite membranes was approximately the same. The thickness of the membranes in dry state varied in a small range between 35 and $45 \mathrm{~nm}$. In this work, the dominant parameter concerning water uptake was the degree of cross-

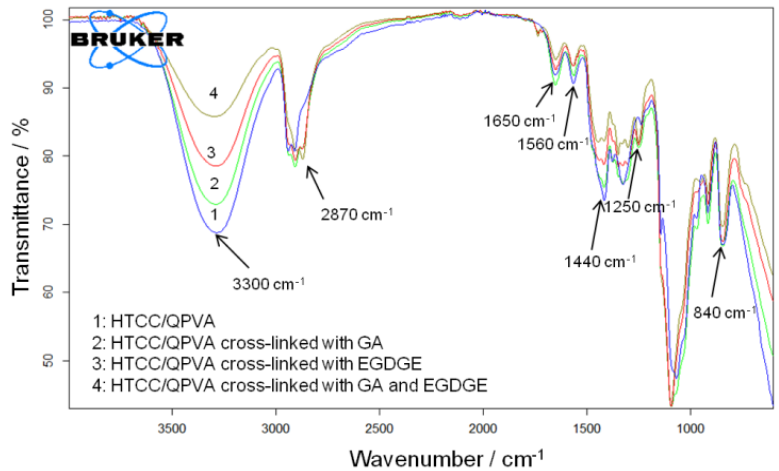

Figure 4: FT-IR spectra of HTCC/QPVA and cross-linked HTCC/QPVA membranes. 
Citation: Feketeföldi B, Cermenek B, Spirk C, Schenk A, Grimmer C, et al. (2016) Chitosan-Based Anion Exchange Membranes for Direct Ethanol Fuel Cells. J Membra Sci Technol 6: 145. doi:10.4172/2155-9589.1000145

Page 6 of 9

linking. The water uptake of the composite membranes cross-linked with GA and EGDGE is given in Figure 5.

A high initial water uptake rate of the composite membranes with a small amount of the first cross-linking agent was obtained (nota bene: The second cross-linking agent was constant). It was found that with an increase in DC percent, the water uptake of the membranes gradually decreased from around $198 \%$ to $98 \%$. This is a consequence of the formation of cross-linked structures with more GA or EGDGE as cross-linking reagents. According to the results, adding GA in the range between DC of $10 \%$ and $50 \%$ causes an increase in cross-linking of the composite membrane, evidenced by lower water uptake. The differences in water uptake can be directly attributed to the varying strong interactions in the polymer matrix by the cross-linkers. The swelling properties of the dried $\left(60^{\circ} \mathrm{C}\right)$ and the heated $\left(130^{\circ} \mathrm{C}\right)$ membranes remained the same over the whole examined range.

\section{Ion exchange capacity (IEC)}

The IEC of anion exchange membranes describes the amount of exchangeable ammonium groups in the membrane, whereby a high IEC basically corresponds to high anion conductivity. The IEC of the composite membranes as a function of amount of cross-linking agents (GA and EGDGE) are given in Figure 6. The results indicate that, at a constant $\mathrm{DQ}$, an increase of the amount of cross-linkers leads to a gradually decreased IEC of the HTCC/QPVA membranes. The highest IEC value is reached at a cross-linker amount of $8.8 \%$ (EGDGE) and $9.1 \%$ (GA), respectively. While the amount of quaternary ammonium groups $\left(\mathrm{R}-\mathrm{N}^{+}\left(\mathrm{CH}_{3}\right)_{3}\right)$ in composite membranes remained constant, the measurable differences observed among IECs can only be associated with the formation of micro-structural modifications of the membranes. A higher water uptake in membranes generates transferring channels and creates a better clearance for ammonium ions, whereas a high amount of cross-linking agents increases the polymer density and restricts the mobility of the polymer functional groups and the ion transport. It is also noted that between DQ of $10 \%$ and $25 \%$, the IEC of the EGDGE-series of membranes is to a lesser extent higher than to the IEC of the GA-series of membranes. The composite membranes exhibit the same behaviour in terms of water uptake and ion exchange capacity. In addition, the alkaline stability of the cross-linked membranes was measured in terms of ion-exchange

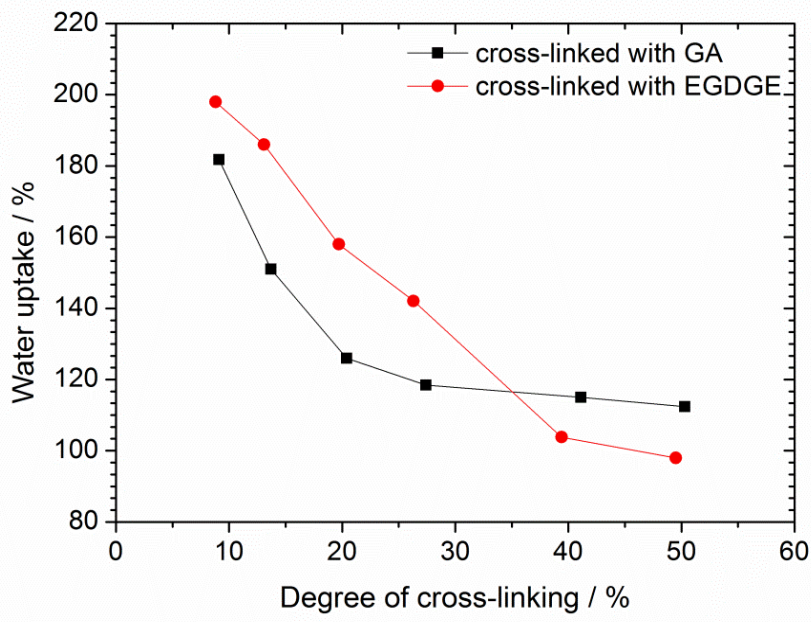

Figure 5: Water uptake of the cross-linked HTCC/QPVA membranes vs. degree of cross-linking. capacity. For this purpose, the membranes were immersed in $1.0 \mathrm{M}$ $\mathrm{KOH}$ solution for $168 \mathrm{~h}$ at $25^{\circ} \mathrm{C}$. The composite membranes showed $80 \%-90 \%$ of their initial IEC due to the degradation of ammonium groups by namely Hofmann elimination and nucleophilic substitution $[41,42]$ (Figures 7 and 8 ).

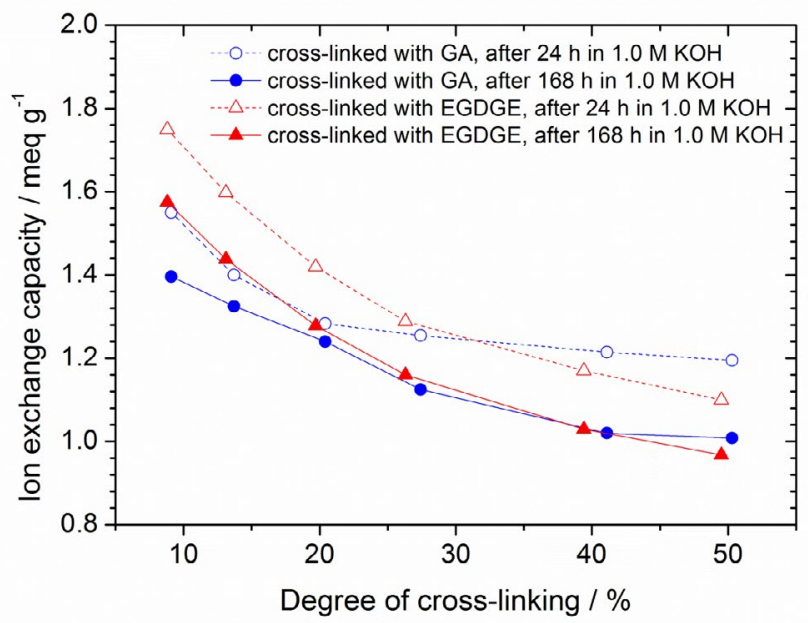

Figure 6: Ion exchange capacity (IEC) of the cross-linked HTCC/QPVA membranes vs. the degree of cross-linking; alkaline treatment for $24 \mathrm{~h}$ and $168 \mathrm{~h}$ in $1.0 \mathrm{M} \mathrm{KOH}$ solution at $25^{\circ} \mathrm{C}$.
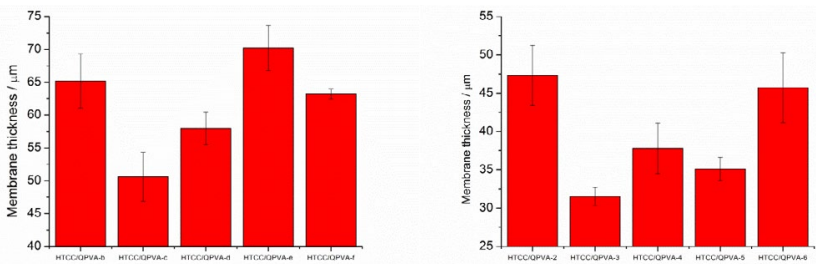

Figure 7: Thickness of the cross-linked HTCC/QPVA membranes (left: b-f with GA; right: 2-6 with EGDGE) in wet state.

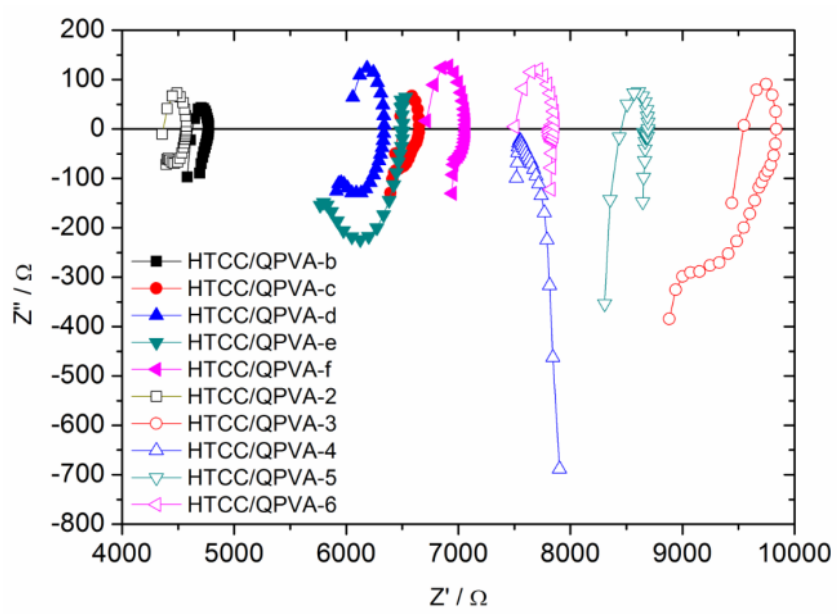

Figure 8: Nyquist plots of the cross-linked HTCC/QPVA membranes (b-f with GA and 2-6 with EGDGE). 
Citation: Feketeföldi B, Cermenek B, Spirk C, Schenk A, Grimmer C, et al. (2016) Chitosan-Based Anion Exchange Membranes for Direct Ethanol Fuel Cells. J Membra Sci Technol 6: 145. doi:10.4172/2155-9589.1000145

Page 7 of 9

\section{Anion conductivity}

Figure 9 shows the anion conductivity of the HTCC/QPVA membranes as a function of the degree of cross-linking after being hydrated for $24 \mathrm{~h}$ at RT using electrochemical impedance spectroscopy (EIS). During EIS measurements, the synthesized anion exchange membranes typically conduct hydroxide ions $\left(\mathrm{OH}^{-}\right)$but also to a very small extent carbonate/hydrogen carbonate ions $\left(\mathrm{CO}_{3}{ }^{2-} / \mathrm{HCO}_{3}{ }^{-}\right)$since the used measurement setup was open to air. Air contains approximately $0.04 \%$ carbon dioxide $\left(\mathrm{CO}_{2}\right)$, which reacts with hydroxide ions to form carbonate [5].

The anion conductivities of all cross-linked membranes range from $7.7 \cdot 10^{-3}$ to $1.61 \cdot 10^{-2} \mathrm{~S} \mathrm{~cm}^{-1}$. It was observed that the anion conductivity decreases with increasing cross-linking density of EGDGE and GA, respectively (Figure 9, right). The highest anion conductivity of the HTCC/QPVA membranes cross-linked with EGDGE and GA was achieved with a cross-linking density of $13.1 \%$ and $13.7 \%$, respectively (Figure 9, right). The thickness of the cross-linked HTCC/QPVA membranes with GA $(51-71 \mu \mathrm{m})$ and EGDGE $(32-47 \mu \mathrm{m})$ does not influence the resulting anion conductivity (Figure 7 and Table 3 ).

According to the results, the IEC and the anion conductivity are determined by the water uptake of the membrane. A high IEC, which is attributed an increased number of quaternary ammonium groups and high water content, results in high anion conductivity due to high migration of anions.

When the DQ of the materials is constant, the IEC, the water uptake and the anion conductivity show a similar trend (Figures 5, 6 and 9). With increasing cross-linking density, which is indirectly correlated to water uptake, the structural anion transport channels alter to narrow microscopic membrane pores, creating a higher resistance for the anions and additionally the active amount of the free ammonium ions are reduced.

\section{Ethanol permeability}

Figure 10 shows the ethanol permeability of the cross-linked composite membranes by EGDGE as a function of degree of crosslinking (DC) at $20^{\circ} \mathrm{C}, 40^{\circ} \mathrm{C}$ and $60^{\circ} \mathrm{C}$ after immersing the membranes in $1.0 \mathrm{M} \mathrm{KOH}$ solutions at RT for $24 \mathrm{~h}$ and $168 \mathrm{~h}$. The ethanol permeability decreases with increasing DC of the membranes. The cross-linking agent EGDGE formed compact structures and a high resistance for ethanol diffusion, which caused a continuously lower ethanol crossover. The ethanol permeability increases with increasing temperature. The average ethanol permeability of the cross-linked composite membranes was $3.17 \cdot 10^{-8} \mathrm{~cm}^{2} \mathrm{~s}^{-1}$ at $20^{\circ} \mathrm{C}, 1.99 \cdot 10^{-7} \mathrm{~cm}^{2} \mathrm{~s}^{-1}$ at $40^{\circ} \mathrm{C}$ and $5.21 \cdot 10^{-7} \mathrm{~cm}^{2} \mathrm{~s}^{-1}$ at $60^{\circ} \mathrm{C}$. Figure 10 shows also the influence of alkaline treatment for 168 hours at RT on the ethanol permeability of the cross-linked membranes. With increasing duration of alkaline
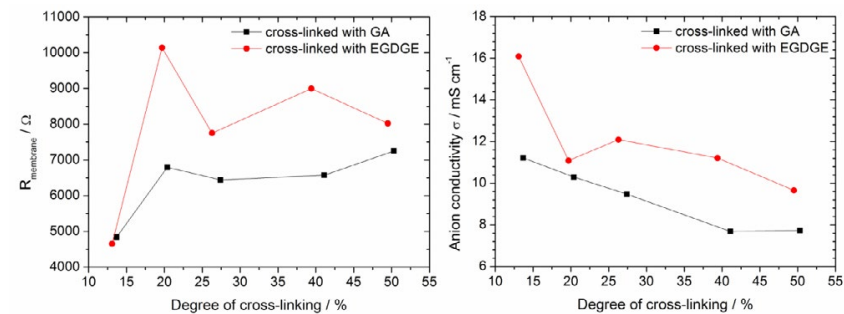

Figure 9: Membrane resistance $R$ (left) and anion conductivity $\sigma$ (right) of the cross-linked HTCC/QPVA membranes vs. the degree of cross-linking. treatment of the membranes from $24 \mathrm{~h}$ to $168 \mathrm{~h}$, the results of the ethanol permeability were not changed at $20^{\circ} \mathrm{C}$ and were slightly higher at $40^{\circ} \mathrm{C}$. These data indicate that the cross-linked membranes have low ethanol permeability and hence a higher tolerance toward ethanol as reported by other studies [21]. However at a temperature of $60^{\circ} \mathrm{C}$, an increase of ethanol diffusion of about $20 \%$ was obtained for pre-treated membranes, due to induced degradation in alkaline medium [38].

A linear correlation of the results between a degree of crosslinking of $20 \%$ and $50 \%$ were obtained (Figure 10). Lower crosslinked membranes ( $\mathrm{DC}<20 \%)$ showed less homogeneous structure. Therefore, the diffusion for non-aqueous media $(1.0 \mathrm{M} \mathrm{EtOH})$ varied and the results were out of the linear region of the permeability measurements.

\section{Scanning electron microscopy (SEM)}

The SEM images for the surface of the annealed membranes crosslinked by GA and EGDGE are shown in Figure 11. The composite membrane without cross-linking shows less compact structure and possible phase separation (Figure 11a). In the network cross-linked by

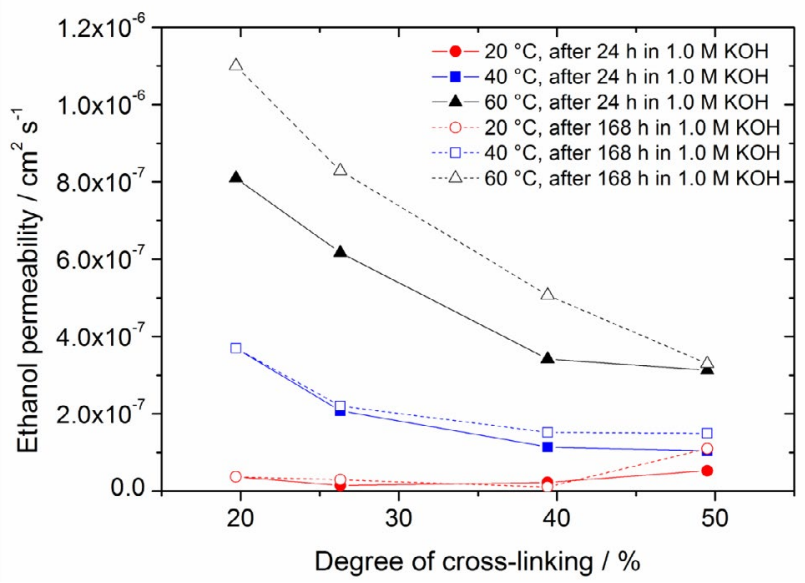

Figure 10: Ethanol permeability of the cross-linked HTCC/QPVA membranes
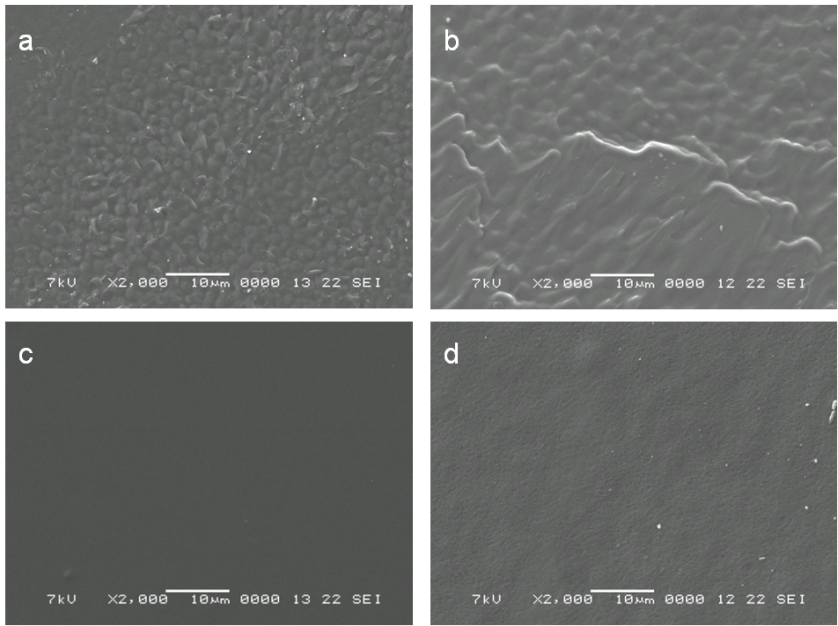

Figure 11: SEM photographs of HTCC/QPVA membranes (a) without crosslinking (b) cross-linked by GA with an amount of $0.6 / 2.2 \mathrm{mmol} \mathrm{mmol}^{-1}$ (c) crosslinked by EGDGE with an amount of $0.6 / 2.2 \mathrm{mmol} \mathrm{mmol}^{-1}$ and (d) cross-linked by GA/EGDGE with an amount of each $0.6 / 2.2 \mathrm{mmol} \mathrm{mmol}^{-1}$. 
GA, a more homogeneous structure was obtained (Figure 11b). The morphology of the HTCC/QPVA membrane cross-linked by EGDGE is shown in Figure 11c. The surface is flat and homogenous and appears denser than the membrane cross-linked by GA. The combination of the cross-linkers EGDGE and GA with an amount of each 0.6/2.2 mmol $\mathrm{mmol}^{-1}$ decreases the uniformity of the membrane structure (Figure 11d). A less compact structure was obtained, which may be attributed to an overloading with cross-linker that caused the membrane to become less stable. The results indicate that the polymers are combined well with both GA and EGDGE as cross-linking agents, but the amount of the agents must be selected within an optimal range.

The bright dots on SEM images can be attributed to debris originating from sample particles. As the membrane samples were slightly brittle and can crumble into pieces to a certain extent and, in addition, the samples were not prepared in a cleanroom environment, such particles are frequently observed. Nevertheless, we do not expect that this would affect the experimental results and data interpretation presented in the manuscript.

\section{Thermogravimetric analysis (TGA)}

The thermal degradation behavior of the HTCC- and QPVApowder and HTCC/QPVA composite membranes cross-linked by EGDGE is shown in Figure 12 . The decrease at around $100^{\circ} \mathrm{C}$ is due to the bonded water evaporation of $7.5 \%$ of all materials. Pure chitosan is thermally not stable enough and starts to degrade continuously at around $120^{\circ} \mathrm{C}$ due to the breakdown of side chains and backbone. By addition of QPVA the composite membrane is stable up to $280^{\circ} \mathrm{C}$. The quaternized PVA powder shows the same thermal gravimetric properties as the composite HTCC/QPVA membrane cross-linked with EGDGE. This indicates that the thermal stability of the membrane is mainly determined by QPVA.

Two stages of thermal degradation were found for the cross-linked membranes. The onset temperature of degradation $\left(\mathrm{T}_{\mathrm{d}}\right)$ of the first stage is about $260^{\circ} \mathrm{C}$, and the degradation temperature of the onset of the second stage is about $380^{\circ} \mathrm{C}$.

Figure 13 shows the TGA curves of the composite membranes cross-linked by EGDGE and GA as well as with a thermal annealing process. In addition to the evaporation of the bonded water, there are two more weight loss regions. The second weight loss occurs within a range of $260-320^{\circ} \mathrm{C}$ due to the degradation of quaternary ammonium

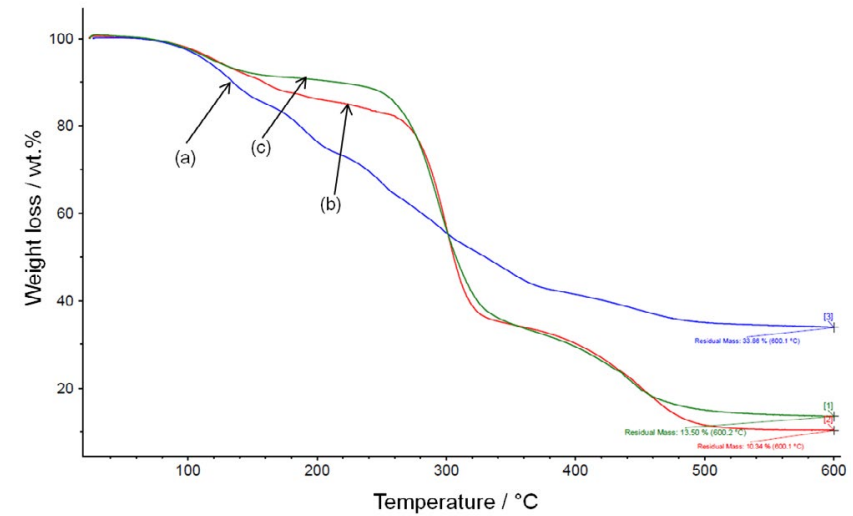

Figure 12: TGA curve of (a) chitosan powder, (b) QPVA-powder and (c) HTCC/ QPVA composite membrane.

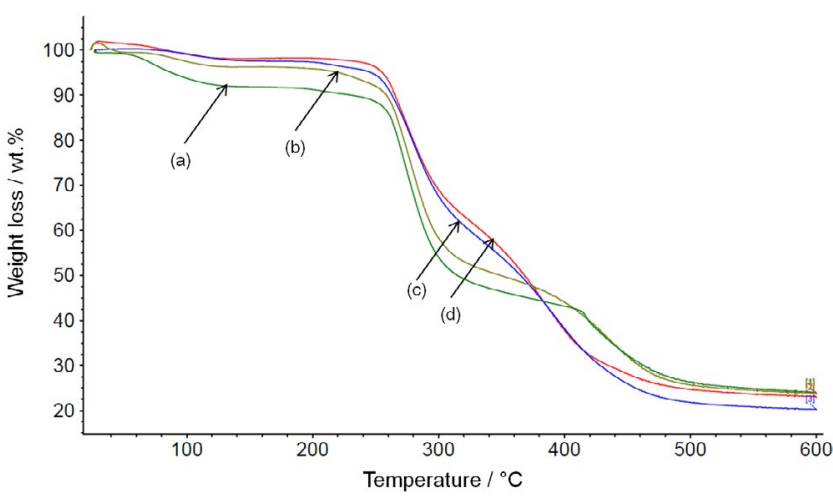

Figure 13: TGA curve of HTCC/QPVA membranes cross-linked by (a) GA, (b) GA annealed, (c) EGDGE and (d) EGDGE annealed.

groups. The weight loss of the membranes cross-linked by EGDGE and GA is about $35 \%$ and $45 \%$, respectively. At the third stage at $320-420^{\circ} \mathrm{C}$, the degradation is attributed to the break of the $\mathrm{C}-\mathrm{C}$ backbone of the main polymer chains. The TGA curves for membranes cross-linked by GA and EGDGE were somewhat different in the region between 260 $420^{\circ} \mathrm{C}$. The decomposition of membranes cross-linked with GA occurs rapidly up to $300^{\circ} \mathrm{C}$ due to the loss of fewer cross-linked hydroxyl groups of the membrane matrix [43]. At this third stage, the weight loss of the membranes cross-linked with EGDGE was slower. It is possible that the cross-linking reaction with EGDGE has formed more stable membranes with increased thermal stability. The total weight loss of the membranes cross-linked by EGDGE and GA is about $75 \%$ and $85 \%$, respectively. The degradation effects of the membranes that were annealed for $2 \mathrm{~min}$ at $130^{\circ} \mathrm{C}$ were less pronounced than of the dried membranes, which can be explained by the formation of stronger three dimensional networks.

\section{Conclusion}

Two series of novel quaternized chitosan/PVA membranes crosslinked with different cross-linking agents were successfully prepared. After subjecting the as-prepared membranes to an additional annealing process, the resulting membranes were characterized toward suitability for direct ethanol fuel cells. The composite membranes showed excellent transport and ionic properties for anions and concurrently a low ethanol permeability. The combined cross-linking strategy enhanced the chemical and thermal stability, as well as the long-term stability in alkaline environment. Furthermore, the developed membranes exhibit a high water uptake leading to superior anion conductivity. The crosslinked and annealed HTCC/QPVA membranes were stable in alkaline solution for $650 \mathrm{~h}$ at $60^{\circ} \mathrm{C}$ and showed less chemical degradation affecting ethanol crossover and ion exchange capacity.

This study demonstrates that the developed novel cross-linked membrane systems meet the benchmark of contemporarily applied membrane technology. Future investigations will focus on the screening of additional polymers to be applied as a high quaternized membrane matrix.

\section{Acknowledgement}

Financial support by the Austrian Climate and Energy Fund, Austrian Federal Ministry of Transport, Innovation and Technology (BMVIT), The Austrian Research Promotion Agency (FFG) and the IEA research cooperation are gratefully acknowledged. 
Citation: Feketeföldi B, Cermenek B, Spirk C, Schenk A, Grimmer C, et al. (2016) Chitosan-Based Anion Exchange Membranes for Direct Ethanol Fuel Cells. J Membra Sci Technol 6: 145. doi:10.4172/2155-9589.1000145

\section{References}

1. Kamarudin MZF, Kamarudin SK, Masdar MS, Daud WRW (2013) Review: Direct ethanol fuel cells. Int J Hydrogen Energy 38: 9438-9453.

2. An L, Zhao T, Li YS (2015) Carbon-neutral sustainable energy technology: Direct ethanol fuel cells. Renewable and Sustainable Energy Reviews 50 1462-1468.

3. Antolini E, Gonzalez ER (2010) Alkaline direct alcohol fuel cells. J Power Sources 195: 3431-3450.

4. Yu EH, Krewer U, Scott K (2010) Principles and Materials Aspects of Direct Alkaline Alcohol Fuel Cells. Energies 3: 1499-1528.

5. Zhao TS, Li YS, Shen SY (2010) Anion-exchange membrane direct ethano fuel cells: Status and perspective. Front Energy Power Eng China 4: 443-458.

6. Xiang Y, Yang M, Guo Z, Cui Z (2009) Alternatively chitosan sulfate blending membranes as methanol-blocking polymer electrolyte membrane for direct methanol fuel cell. J Memb Sci 337: 318-323.

7. Buraidah $\mathrm{MH}$, Arof AK (2011) Characterization of chitosan/PVA blended electrolyte doped with NH4I. J Non Cryst Solids 357: 3261-3266.

8. Smitha B, Sridhar S, Khan AA (2005) Synthesis and characterization of poly(vinyl alcohol)-based membranes for direct methanol fuel cell. J Appl Polym Sci 95: 1154-1163.

9. Binsu VV, Nagarale RK, Shahi VK, Ghosh PK (2006) Studies on N-methylene phosphonic chitosan/poly(vinyl alcohol) composite proton-exchange membrane. React Funct Polym 66: 1619-1629.

10. Meenakshi S, Bhat SD, Sahu AK, Sridhar P, Pitchumani S, et al. (2012) Chitosanpolyvinyl alcohol-sulfonated polyethersulfone mixed-matrix membranes as methanol-barrier electrolytes for DMFCs. J Appl Polym Sci 124: E73-E82.

11. Ma J, Sahai Y (2013) Chitosan biopolymer for fuel cell applications. Carbohydrate Polymers 92: 955-975.

12. Couture G, Alaaeddine A, Boschet F, Ameduri B (2011) Polymeric materials as anion-exchange membranes for alkaline fuel cells. Prog Polym Sci 36: 1521 1557.

13. Merle G, Wessling M, Nijmeijer K (2011) Anion exchange membranes for alkaline fuel cells: A review. J Memb Sci 377: 1-35.

14. Gavhane YN, Gurav AS, Yadav AV (2013) Chitosan and Its Applications: A Review of Literature. Int J Res Pharmaceut Biomed Sci 4: 312-331.

15. Moulay S (2015) Review: Poly(vinyl alcohol) Functionalizations and Applications. Polym Plast Technol Eng 54: 1289-1319.

16. Wan Y, Peppley B, Creber KAM, Bui VT, Halliop E (2006) Preliminary evaluation of an alkaline chitosan-based membrane fuel cell. J Power Sources 162: 105113.

17. Wan Y, Creber KAM, Peppley B, Bui VT (2006) Chitosan-based electrolyte composite membranes II. Mechanical properties and ionic conductivity. J Memb Sci 284: 331-338.

18. Wan Y, Creber KAM, Peppley B, Bui VT (2006) Chitosan-based solid electrolyte composite membranes: I. Preparation and characterization. J Memb Sci 280 : 666-674.

19. Xiong Y, Fang J, Zeng QH, Liu LQ (2007) Preparation and characterization of cross-linked quaternized poly(vinyl alcohol) membranes for anion exchange membrane fuel cells. J Memb Sci 311: 319-325.

20. Xiong Y, Liu QL, Zhang QG, Zhu AM (2008) Synthesis and characterization of cross-linked quaternized poly(vinyl alcohol)/chitosan composite anion exchange membranes for fuel cells. J Power Sources 183: 447-453.

21. Yang JM, Chiu HC (2012) Preparation and characterization of polyvinyl alcohol/ chitosan blended membrane for alkaline direct methanol fuel cells. J Memb Sci 419-420: 65-71.

22. Vogel C, Meier-Haack J (2014) Preparation of ion-exchange materials and membranes. Desalination 342: 156-174.

23. Berger J, Reist M, Mayer JM, Felt O, Peppas NA, et al. (2004) Structure and interactions in covalently and ionically cross-linked chitosan hydrogels for biomedical applications. Eur J Pharm Biopharm 57: 19-34.

24. Bolto B, Tran T, Hoang M, Xie Z (2009) Cross-linked poly(vinyl alcohol) membranes. Prog Polym Sci 34: 969-981.
25. Gupta KC, Jabrail FH (2006) Glutaraldehyde and glyoxal cross-linked chitosan microspheres for controlled delivery of centchroman. Carbohydrate Research 341: 744-756.

26. Pauliukaite R, Ghica ME, Fatibello-Filho O, Brett CMA (2010) Electrochemical impedance studies of chitosan-modified electrodes for application in electrochemical sensors and biosensors. Electrochimica Acta 55: 6239-6247.

27. Liu R, Xu X, Zhuang X, Cheng B (2014) Solution blowing of Chitosan/PVA hydrogel nanofiber mats. Carbohydrate Polymers 101: 1116-1121.

28. Zhang D, Zhou W, Wei B, Wang X, Tang R, et al. (2015) Carboxyl-modified poly(vinyl alcohol)-crosslinked chitosan hydrogel films for potential wound dressing. Carbohydrate Polymers 125: 189-199.

29. Zhang J, Qiao J, Jiang G, Liu L, Liu Y (2013) Cross-linked poly(vinyl alcohol)/ poly (diallyldimethylammonium chloride) as anion-exchange membrane for fuel cell applications. J Power Sources 240: 359-367.

30. Wan Y, Peppley B, Creber KAM, Buia VT, Halliop E (2008) Quaternizedchitosan membranes for possible applications in alkaline fuel cells. J Power Sources 185: 183-187.

31. Liao GM, Yang CC, Hu CC, Pai YL, Lue SJ (2015) Novel quaternized polyviny alcohol/quaternized chitosan nano-composite as an effective hydroxideconducting electrolyte. J Memb Sci 485: 17-29.

32. Wu J, Su ZG, Ma GH (2006) A thermo- and pH-sensitive hydrogel composed of quaternized chitosan/glycerophosphate. Int J Pharmaceutics 315: 1-11.

33. Shin MS, Byun YJ, Choi YW, Kang MS, Park JS (2014) On-site crosslinked quaternized poly(vinyl alcohol) as ionomer binder for solid alkaline fuel cells. Int J Hydrogen Energy 39: 16556-16561.

34. Tian G, Liu L, Meng Q, Cao B (2014) Preparation and characterization of crosslinked quaternised polyvinyl alcohol membrane/activated carbon composite electrode for membrane capacitive deionization. Desalination 354: 107-115.

35. Bodner M, Cermenek B, Rami M, Hacker V (2015) The Effect of Platinum Electrocatalyst on Membrane Degradation in Polymer Electrolyte Fuel Cells. Membranes 5: 888-902.

36. Ranacher C, Resel R, Moni P, Cermenek B, Hacker V, et al. (2015) Layered Nanostructures in Proton Conductive Polymers obtained by initiated Chemical Vapor Deposition. Macromolecules 48: 6177-6185.

37. Dedmond E, Cooper K (2016) Application Note - Effect of Solution Conductivity on In-Plane Membrane Conductivity Measurement.

38. Wang J, He R, Che Q (2011) Anion exchange membranes based on semiinterpenetrating polymer network of quaternized chitosan and polystyrene. J Colloid Interface Sci 361: 219-225.

39. Merle G, Schwan Hosseiny S, Wessling M, Nijmeijer K (2012) New cross-linked PVA based polymer electrolyte membranes for alkaline fuel cells. J Memb Sci 409: 191-199.

40. Peng ZX, Wang L, Du L, Guo SR, Wang XQ, et al. (2010) Adjustment of the antibacterial activity and biocompatibility of hydroxypropyltrimethyl ammonium chloride chitosan by varying the degree of substitution of quaternary ammonium. Carbohydrate Polymers 81: 275-283.

41. Lim SH, Hudson SM (2004) Synthesis and antimicrobial activity of a watersoluble chitosan derivative with a fiber-reactive group. Carbohydrate Research 339: 313-319.

42. Varcoe JR, Poynton SD, Slade RCT (2009) Handbook of Fuel Cells: Advances in Electrocatalysis, Materials, Diagnostics and Durability - Fundamentals, Technology and Applications. Wiley.

43. Ye L, Zhai L, Fang J, Liu J, Li C, et al. (2013) Synthesis and characterization of novel cross-linked quaternized poly(vinyl alcohol) membranes based on morpholine for anion exchange membranes. Solid State lonics 240: 1-9. 